\title{
MAPEAMENTO FUNCIONALISTA DO ITEM TIPO EM CONTEXTOS ORAIS PARAIBANOS
}

\section{LINGUISTIC MULTI-FUNCTION MAPPING OF THE ITEM TIPO IN PARAÍBA'S STATE}

\author{
Aymmée Silveira Santos ${ }^{1}$ \\ Camilo Rosa Silva ${ }^{2}$ \\ Universidade Federal da Paraíba
}

\section{RESUMO}

O papel dos usuários de uma língua é indispensável aos estudos funcionalistas e à concepção de uma gramática emergente. Uma das formas de materialização do processo comunicacional de modo eficaz e produtivo ocorre quando os indivíduos constroem novas funções ou sentidos no discurso, com a mudança sintático-semântica de um item ou construção linguística. Com base na perspectiva funcionalista, percebe-se que o item tipo está exercendo gramaticalmente novas funções, como a de conector comparativo. O presente estudo visa descrever o mapeamento das multifunções do item tipo em contexto oral paraibano, a partir de entrevistas disponibilizadas no corpus VALPB - Projeto Variação Linguística do Estado da Paraíba. O trabalho se fundamenta em aportes da linguística funcional, dialogando com autores como Givón (1979), Hopper (1991), Martelotta (2011), entre outros. Os resultados demonstram que os falantes estão utilizando o item tipo com funções distintas, reforçando as estratégias de gramaticalização desenvolvidas pelos falantes durante a atividade comunicativa, como, por exemplo, os princípios de Hopper (1991), embora ainda prevaleça o uso da função tradicional de tipo, isto é, a de substantivo.

PALAVRAS-CHAVE: funcionalismo; gramaticalização; multifunções; tipo

\begin{abstract}
The speeches from users of a language are indispensable for functional studies and for the design of an emerging grammar. One of the ways to materialize the communicational process, effectively and productively, occurs when speakers construct new functions or meanings in speech, with a syntactic-semantic change of an item or linguistic construction. Based on the functionalist perspective, it is clear that the Brazilian Portuguese Language item tipo (type - translated to English) is grammatically exercising new functions such as the comparative connector in that language. This aims at a describing the linguistic multifunction mapping of the item tipo in the oral context in Paraiba (Brazilian state), from interviews available in the 'Projeto Variação Linguística - VALPB (1993)' (Linguistics Variation Project - VALPB from 1993). This work is based on of functional linguistics, dialoguing with contributions by authors such as Givón (1979), Hopper (1991) and Martelotta (2011), among others. The results demonstrated that the speakers are using the item tipo with multi-functions, reinforcing the strategies of grammaticalization developed by the speakers during the communicative activity, although the traditional function of the item tipo, the noun, still prevails.
\end{abstract} KEY-WORDS: functional linguistics; grammaticalization; multi-functions; item tipo.

\footnotetext{
${ }^{1}$ Graduada em Letras pela Universidade Federal de Campina Grande e Mestra em Linguística pela Universidade Federal da Paraíba. E-mail: aymmeesst@gmail.com

2 Doutor em Letras, Professor do Programa de Pós-Graduação em Linguística da Universidade Federal da Paraíba. Email: camilorosa@gmail.com
} 


\section{INTRODUÇÃO}

Ancorado na Linguística Funcionalista, o presente estudo decorre de uma pesquisa mais ampla sobre a gramaticalização do item tipo e suas multifunções. Partindo de uma abordagem quantitativa e, posterior análise qualitativa dos dados, objetivamos descrever o comportamento multifuncional do item tipo em contextos orais paraibanos, enfatizando sua função de conector comparativo. Daí, desdobram-se os seguintes objetivos específicos: i) atestar a frequência dos usos do item tipo em contexto de comunicação oral paraibano, através de sua quantificação; ii) apresentar as ocorrências do item tipo nas categorias lexical e gramatical; iii) identificar e analisar as multifunções do item tipo, a partir do fenômeno de gramaticalização, dando ênfase à função de conector comparativo.

O corpus VALPB - Projeto Variação Linguística do Estado da Paraíba, cujos dados servem à análise, é constituído por entrevistas. Nesse corpus, foram selecionadas entrevistas coletadas de falantes originários de João Pessoa - Paraíba, abrangendo um total de 48 (quarenta e oito) informantes.

A temática ora enfocada se faz relevante ao verificarmos que há poucos estudos sobre gramaticalização do item tipo. Os estudos até então desenvolvidos sobre o item advêm, em sua maioria, de regiões do Sudeste do país ${ }^{3}$, o que torna oportuno se fazer uma análise do comportamento local deste item, para identificar se os falantes de João Pessoa (região onde não há identificação de registro de pesquisas sobre tipo) demonstram (ou não) a manifestação do processo de gramaticalização de tipo.

Este trabalho organiza-se em quatro seções. A primeira seção discorre sobre o funcionalismo norte-americano e a concepção de gramática proveniente desta perspectiva teórica. A segunda seção explana algumas considerações acerca do que vem a ser o fenômeno de gramaticalização. A terceira seção apresenta os significados do item tipo nos dicionários. Por fim, a quarta seção é dedicada à análise do item tipo no corpus VALPB, contemplando sua frequência de uso nas categorias lexicais e gramaticais e suas multifunções.

\section{O funcionalismo norte-americano: concepção de gramática}

Considerando o indivíduo o elemento central para as discussões linguísticas, o Funcionalismo Norte-americano surge nos Estados Unidos, a partir da década de 1970, dando destaque para o trabalho de linguistas como Sandra Thompson, Paul Hopper e Talmy Givón. O funcionalismo leva em conta que a sintaxe de uma língua possui estruturas em constante mutação, originadas do discurso e das estratégias de organização das informações elaboradas pelos falantes durante a atividade comunicativa. Nesse sentido, a contextualização da língua na situação interacional a que as estruturas se correlacionam também confere grande relevância à pragmática.

A gramática funcional (doravante GF) constitui uma teoria em que há uma relação não arbitrária entre o aspecto funcional e o gramatical da língua, sendo, portanto, uma gramática flexível e adaptável, que considera a língua em situações de uso.

Segundo Neves (1997), a GF leva em conta o falante, o ouvinte, seus papéis e seu estatuto dentro da situação de interação determinada socioculturalmente, tendo em vista que a descrição da estrutura da sentença não é suficiente para determinar o significado da expressão linguística.

Nesse sentido, no contexto dos estudos funcionalistas surge a noção de gramática emergente, desenvolvida por Hopper (1993), entendida como uma gramática passível de mudança e

\footnotetext{
${ }^{3}$ Lima-Hernandes (2005), em sua tese de doutorado, evidenciou o fenômeno de gramaticalização do item tipo em algumas revistas de circulação nacional. A autora identificou tanto a função tradicional de substantivo, como também funções exemplificativas e comparativas-aproximativas. Thompson (2013), em sua dissertação de mestrado, fez uma análise hallidayana de cláusulas decorrentes do uso de tipo em três diferentes classes: a dos substantivos, a dos articuladores e a dos marcadores discursivos. A autora coletou os dados nos corpora D\&G- RJ, Varport, em roteiros de cinema brasileiro e postagens da rede social Facebook.
} 
substancialmente afetada por seu uso constante, em que novas estruturas gramaticais se desenvolvem. Desse modo, consequentemente, a regularidade da gramática é apenas provisória e nunca totalmente completa. De acordo com Givón (1991), a língua não pode ser descrita como um sistema autônomo, uma vez que a gramática não é um sistema de conhecimento estável, mas é continuamente constituído.

Enquanto que para os formalistas, a gramática é separável do discurso, e o precede, para os funcionalistas, a gramática é organizada por um conjunto de regras observáveis nos usos linguísticos, as quais emergem do discurso. Segundo o ponto de vista funcionalista, especialmente o de Hopper (1987), a rigor, não existe gramática, o que existe é a gramaticalização, processo ao mesmo tempo sincrônico e diacrônico.

Sob essa perspectiva, novas estruturas linguísticas estão surgindo a todo momento e, devido a isso, umas se tornam arcaicas, algumas são tidas como padrão a ser seguido pela gramática da linguagem formal e algumas se encontram em competição com as já existentes. Assim, refuta-se a noção de que há uma gramática pronta e acabada, pois a língua vai além da estrutura gramatical, sendo o contexto de grande importância para a compreensão do seu funcionamento.

Nesse sentido, a noção de gramática adotada pela corrente funcionalista é a de sistema adaptativo, que é emergente, estando em constante reformulação num processo nunca totalmente completado. Gramática, portanto, não se desmembra de discurso, uma vez que ambos interferem um no outro a partir dos usos que os falantes fazem das estruturas linguísticas, quando novas estruturas vão surgindo nas interações diversas.

Conforme salientam Oliveira e Votre (2009, p. 105), o conceito de discurso, modernamente, faz referência "às estratégias criativas dos usuários na organização de sua produção linguística aos modos individuais com que cada membro da comunidade elabora suas formas de expressão". Já o conceito de "gramática", conforme asseveram os mesmos estudiosos, é associado ao "conjunto das regularidades linguísticas, como o modo ritualizado ou comunitário do uso". Consequentemente, as ideias de liberdade/ autonomia voltam-se ao discurso e as noções de sistematização/regularização relacionam-se à noção de gramática. No entanto, os autores salientam que discurso e gramática estão imbricados:

\footnotetext{
os fatores de natureza pragmático-comunicativa não só podem ser responsáveis pela regularização gramatical, como também atuam na seleção e na organização daquilo que a própria gramática atualiza. Em outros termos, uma vez sistematizados, os constituintes gramaticais são usados conforme as condições interacionais, são dependentes de fatores que marcam as práticas envolvidas no uso (p. 105)
}

Além disso, as "novas estruturas" criadas pelos falantes dificilmente constituem-se de novas formas linguísticas, o que representa, de acordo com Heine (1994), o recrutamento de velhas formas para novos significados. Assim, é comum a utilização de itens e construções lexicais para usos mais gramaticais, ou ainda, para usos com finalidades discursivas e interacionais. Tal fenômeno, chamado gramaticalização, será visto adiante.

Ainda contemplando o pensamento funcionalista, na seção a seguir, serão feitas algumas considerações acerca do fenômeno de gramaticalização.

\section{O fenômeno da gramaticalização}

Esta seção apresenta o fenômeno da gramaticalização e seus diversos conceitos que, no decorrer dos anos, passaram por modificações e contribuíram com o desenvolvimento dos estudos sobre o funcionalismo.

O estudo do fenômeno denominado gramaticalização teve seu desenvolvimento de maneira mais expressiva na Linguística Funcionalista norte-americana durante os anos de 1970. Essa abordagem estuda as mudanças linguísticas, considerando o(s) objetivo(s) da interação durante a atividade comunicativa, os participantes e o contexto discursivo. Assim, "a gramática é vista como 
uma estrutura aparentemente fixa, congelada, mas que é criada e recriada por motivações comunicativas e cognitivas" (CEZARIO, 2012, p. 19).

Alguns estudos de gramaticalização têm privilegiado o viés diacrônico, isto é, preocupação mais voltada para a explicação de como as formas gramaticais surgem e se desenvolvem na língua (cf. GONÇALVES et al, 2007, p. 16). Assim, o viés sincrônico, cuja preocupação está mais voltada para a identificação de graus de gramaticalidade que uma forma linguística desenvolve a partir dos deslizamentos funcionais a ela conferidos pelos padrões fluidos de uso da língua (cf. GONÇALVES et al, 2007, p. 16), fica em segundo plano. No entanto, em verdade, não há como separar os dois vieses definitivamente, pois a gramaticalização é de caráter pancrônico, isto é, combina diacronia e sincronia.

Nessa perspectiva, Hopper (1987, apud NEVES, 2002) afirma que, subjacente à compreensão do processo de gramaticalização, há uma concepção de "língua como atividade no tempo real e a postulação de que, a rigor, não há gramática como produto acabado, mas sim constante gramaticalização”. (p. 176). Além disso, Neves (2002) afirma que a gramaticalização, no campo da Linguística Funcionalista, se preocupa com a função como centro condutor da reflexão, entendendo função como a união entre o estrutural e o funcional, e não apenas como uma entidade sintática. Assim, as diversas funções dos itens e suas diferentes significações no enunciado estão em consonância com a eficiência da comunicação entre os usuários de uma língua.

No entanto, antes de se chegar a essa concepção do que vem a ser gramaticalização, vários estudiosos apresentaram definições a respeito desse fenômeno. A primeira, proposta por Meillet (1912 apud GONÇALVES et al, 2007), cunhador do termo "gramaticalização", se refere à "passagem de uma palavra autônoma à função de elemento gramatical", realizando o percurso léxico > gramática. Desse modo, essa noção considera que a gramaticalização é o fenômeno em que as palavras lexicais de categorias mais plenas (leiam-se nomes, verbos e adjetivos) passam a se integrar a classes de categorias gramaticais (preposições, verbos auxiliares, advérbios). Justificando a relevância da gramaticalização nas atividades da ciência da linguagem, os primeiros estudos desenvolvidos por Meillet dão ênfase à ideia de que a gramaticalização é uma ferramenta da linguística histórica, cujos objetivos eram explicar as origens e mudanças típicas de morfemas gramaticais, contribuindo para a etimologia e evolução histórica das palavras.

Mesmo assim, ao serem observadas as explicações e exemplificações de palavras que passaram pelo processo de gramaticalização por estudiosos da área, concluiu-se que os estudos de Meillet não se distanciam da noção de que o fenômeno em questão é também um processo sincrônico, tal como afirmam Gonçalves et al. (2007), visto que "na perspectiva diacrônica, palavras acessórias e palavras gramaticais podem se desenvolver de palavras principais e, na perspectiva sincrônica, palavras acessórias e/ou gramaticais e sua forma-fonte principal podem conviver num mesmo recorte de tempo" (p. 21-22).

Lehmann (1995 [1982], p. 11-12 apud GONÇALVES et al, 2007) acrescenta à definição de Meillet (1912 apud GONÇALVES et al, 2007) a noção de que o processo de gramaticalização pode levar à mudança não somente de um item lexical para gramatical, mas de um item menos gramatical para mais gramatical. Sua definição corrobora a adotada por Heine et al (1991 apud GONÇALVES et al, 2007): "a gramaticalização consiste no crescimento dos limites de um morfema que avança de um valor lexical para um valor gramatical ou do menos para o mais gramatical, isto é, de um formante derivacional para um formante flexional" (p.03).

Buscando ampliar a noção de gramaticalização, Givón (1979), sem desprezar as ideias defendidas anteriormente pelos teóricos citados, introduz a noção do discurso, através do qual a gramática é produzida. Entendido como uma macrossintaxe, o discurso é constituído através do processo de interação linguística na sociopragmática, sendo uma entidade que influencia o desenvolvimento de estruturas e categorias gramaticais. É com base nessa definição de discurso que este estudo será feito.

Partindo do discurso para a morfossintaxe, perspectiva adotada também por outros estudiosos- Genetti (1991), Haiman (1991), Herring (1991), Hook (1991), Hopper (1991), entre 
outros-, Givón (1979) representa os processos de regularização do uso da língua da seguinte maneira: Discurso $>$ Sintaxe $>$ Morfologia $>$ Morfofonologia $>$ Zero. Ou seja, os itens ou construções lexicais começam a ser utilizados no discurso e, embora possibilitem significar determinada função gramatical, sua função não é fixa ou sistemática. Ao serem utilizados de maneira recorrente pelos indivíduos, esses itens vão se tornando mais regulares, com determinada estruturação sintático-morfológica e, ao se cristalizarem, vão perdendo sua variação sintagmática no uso. Assim, ao passo que os itens vão se fixando na língua, sua ordem vai ficando mais rígida, como, por exemplo, causando a impossibilidade da ocorrência de inversões de elementos. Durante a frequência de uso, os itens podem sofrer alterações fonológicas ou até mesmo desaparecer, podendo atingir o grau zero, para que, consequentemente, outro item o substitua funcionalmente, e recomece outro ciclo funcional.

Outro aspecto concernente à gramaticalização, de acordo com Martellota (2011), é o fato de que esse processo envolve não apenas elementos fixos e regulares que assumem restrições gramaticais de um ponto de vista mais formal, mas também elementos sintaticamente mais livres que veiculam estratégias discursivo-pragmáticas, como, por exemplo, os marcadores discursivos e outros elementos interpessoais. Sendo assim, no processo de gramaticalização, o modo mais pragmático de comunicação possibilita um modo mais sintático, e expressões linguísticas sintaticamente mais fracas se transformam em expressões sintaticamente mais fortes.

A gramaticalização, já mencionada anteriormente, é definida por Martelotta (2011) como o processo de desenvolvimento de estruturas gramaticais a partir de estruturas lexicais e de estruturas mais gramaticais a partir de estruturas menos gramaticais, vem contribuindo para uma melhor compreensão de como funciona o fenômeno da mudança linguística. É através da gramaticalização que os falantes fazem o uso de certas palavras em contextos que não são os seus de origem, criando novas expressões ou adotando novos sentidos para expressões já existentes, com vistas a tornar mais eficiente e eficaz o processo comunicacional. Ao longo do tempo, uma nova construção gramatical resultante pode continuar a receber novas funções gramaticais e, nesse sentido, a mudança, conforme defendem os funcionalistas, tenderá sempre a se desenvolver de uma função mais concreta para outra mais abstrata.

Segundo Heine e Reh (1984 apud HEINE et al.,1991), quando uma unidade linguística passa pelo processo de gramaticalização, perde complexidade semântica e valor expressivo, já que deixa de funcionar como uma categoria lexical, que representa algo no mundo. A unidade linguística também ganha mais significação sintática, já que se torna um item gramatical ou mais gramatical e a sua posição na oração vai se tornando mais fixa. Por fim, há uma aglutinação semântica, morfossintática e fonética com outras unidades e perda de substância fonética.

Devido a esses aspectos, os estudiosos chegaram à conclusão de que a gramaticalização é um continuum evolutivo, influenciada por vários fatores, como o nosso aparato neurofisiológico, nosso ambiente sociocultural, o contexto no qual nós agimos, o contato linguístico, a interferência entre a forma escrita e a forma falada de uma determinada língua etc.

\section{Como o tipo é visto nos dicionários}

Julgamos relevante apresentar como o item tipo é tratado por lexicógrafos, com vistas a observar a categoria original da qual faz parte. Para isso, foi selecionado o dicionário virtual Léxico ${ }^{4}$, além dos dicionários Aurélio e Houaiss. O primeiro tendo em vista que dicionários virtuais são utilizados com frequência atualmente, sendo este bem consistente em relação à dimensão quantitativa dos significados apresentados, e os dois últimos, por serem no Brasil, provavelmente, os compêndios mais utilizados por usuários em geral. Os significados registrados para o item em questão, nestes dicionários, são apresentados, respectivamente:

4 O Léxico é um dicionário online de português com mais de 320.000 palavras registradas, com diversos significados e definições de vocábulos da língua portuguesa. 
Significado de Tipo

subst. m.

1. conjunto de características que distinguem uma classe: um tipo de cães

2. indivíduo, homem: um tipo alto

3. modelo, estilo: Ele é o tipo do machão.

(Disponível em: bttp:/ / www.lexico.pt/ tipo/)

Ti.po: s.m. 1. Coisa que reúne em si os caracteres distintivos duma classe. 2. Exemplar, modelo. 3. Fam. Pessoa esquisita, excêntrica. 4. Qualquer indivíduo. 5. Tip. Peça de metal fundida, cujo relevo imprime determinada letra ou sinal. 6. Tip. Letra impressa, caráter. (Dicionário Aurélio, 2000)

Ti.po s. m. 1 objeto ou coisa us. para produzir outro igual; modelo. 2 categoria de seres ou objetos agrupados segundo algumas características; espécie <carros desse t. são caros $>$. 3 conjunto de características de uma família, povo ou região etc. $<$ t. eslavo $>$. 4 GRÁF bloco de metal fundido ou de madeira, que traz em uma das faces, gravação em relevo de um sinal de escrita. 5 GRÁF caráter ('sinal'), letra 6 inform. Qualquer indivíduo; sujeito <era um t. gozador>. (Dicionário Houaiss da Língua Portuguesa, 2001)

Conforme se pode observar nos dicionários, o termo tipo funciona, originalmente, como substantivo masculino, fazendo parte, portanto, da categoria lexical, significando, de modo geral, um termo para distinguir algo ou alguém ou, ainda, servindo como equivalente a modelo, de forma que definições relativas ao indivíduo são mais concretas em relação, por exemplo, às definições equivalentes à espécie.

Com descrições semelhantes, os dicionários Aurélio e Houaiss apresentam o elemento de origem lexical para se referir a um indivíduo esquisito, a letra impressa da máquina de tipografia, denotando sentidos mais concretos, ou a um modelo, espécie, ou exemplar, com sentido mais abstrato em relação aos anteriormente mencionados. Também é relevante destacar que o dicionário virtual em todas as ocasiões apresenta um exemplo, o que facilita a demonstração do comportamento do item com os significados expostos.

\section{As multifunções do item tipo no corpus de análise}

\subsection{Ocorrências de tipo nas categorias lexical e gramatical}

Nesta seção, achamos conveniente descrever o tipo conforme sua distribuição em categorias lexicais e gramaticais, tendo em vista que consideramos importante analisar a proporção de uso de tipo em sua categoria original e em categoria gramatical, demonstrando funções mais inovadoras do item, quais sejam, a função exemplificativa e a de marcador discursivo.

Retomando a conceituação apresentada por Martelotta (2011), a gramaticalização é o fenômeno em que itens de categoria lexical, como substantivos e verbos, passam a exercer funções gramaticais, a exemplo das conjunções. Nesse sentido, com o intuito de observar a frequência de ocorrências entre a categoria original e a categoria gramatical, em que se enquadram os usos inovadores do item tipo, obtivemos o resultado representado na tabela 01, a seguir, contendo os dados do corpus VALPB:

Tabela 01: Distribuição do item tipo em categorias lexicais e gramaticais 
De acordo com a tabela 01, no corpus VALPB houve a prevalência de ocorrências de tipo na

\begin{tabular}{|c|c|c|c|}
\hline Corpus de análise & Categoria lexical & $\begin{array}{c}\text { Categoria } \\
\text { gramatical }\end{array}$ & Total \\
\hline VALPB & 188 & 31 & 219 \\
\hline
\end{tabular}

categoria lexical em relação à categoria gramatical, ou seja, a categoria original dos itens se sobrepõe ao uso de tipo com funções mais recentes, que se enquadram na categoria gramatical. Embora o item tipo tenha passado por mudanças de uso, exercendo funções que não somente as próprias de substantivo, o tipo- substantivo ainda prevalece nos dados analisados, talvez porque seja mais aceito na língua portuguesa culta do que suas funções gramaticais, que são evidenciadas com maior frequência em contextos cotidianos, informais, e não em contextos relativamente monitorados, menos informais.

Para uma melhor visualização desses comportamentos, selecionamos alguns exemplos retirados do corpus, conforme seguem:

(01) $\mathrm{F}^{*}$ Quando eu era criança o tipo de brincade0ra que eu mais gostava : por incrível que pareça eu [brin-] gostava de brincar só.

(02) I* Eu gosto + eu gosto do Jornal Nacional, gosto da novela das oito, + e todo tipo de desenho que passa. Desenho animado. + Gosto de filme, né? também assim. Que passa assim depois da da novela das oito. Se for um filme bom, eu gosto também.

(03) I* Futebol de campo é assim um atrativo, né? Mays eu gosto de assisti:ø futebol, qualquéø tipo de futebol, pode sêø até futebol americano.

As ocorrências (01), (02) e (03) apresentam exemplos em que o tipo se classifica como substantivo, sendo enquadrado, portanto, na categoria lexical. De acordo com os significados contidos nos dicionários Léxico, Aurélio e Houaiss, vemos que em (01) o tipo foi utilizado com a finalidade de evidenciar o estilo de brincadeira que a informante mais gostava quando era pequena. Em (02) e (03), respectivamente, o tipo é empregado para fazer referência aos estilos de desenho animado e para o informante esclarecer que gosta de assistir a jogos de qualquer estilo de futebol.

Em razão de termos identificado diferentes funções de tipo que estão enquadradas na categoria gramatical, na próxima seção, descreveremos estas funções.

\subsection{As funções de tipo na categoria gramatical}

Inicialmente, a tabela 02 apresenta a quantificação de ocorrências em que tipo foi utilizado com funções gramaticais no corpus VALPB. Elas foram classificadas em exemplificativas, conectivas comparativas e marcadores discursivos.

Tabela 02: Distribuição das ocorrências de tipo com valor gramatical por função

Já que o valor comparativo do item tipo será objeto de análise na próxima seção, as funções

\begin{tabular}{|c|c|c|c|c|}
\hline $\begin{array}{c}\text { Corpus de } \\
\text { análise }\end{array}$ & $\begin{array}{c}\text { Função } \\
\text { exemplificativa }\end{array}$ & $\begin{array}{c}\text { Função } \\
\text { comparativa }\end{array}$ & $\begin{array}{c}\text { Função de } \\
\text { marcador } \\
\text { discursivo }\end{array}$ & Total \\
\hline VALPB & 22 & 07 & 01 & 30 \\
\hline
\end{tabular}

exemplificativa e de marcador discursivo são demonstradas nos exemplos, a seguir:

(04) I* Não. Eu não acredito em [pro-], quer dizer, eu [pe-]+ tenho promessa mays: peço a Deus, mais: tipo você pedir um: fazeø uma promessa pra pediø a um santo qualquer, 
não. Não peço. Já pedi, antes de: conhecer realmente a palavra de Deus, já cheguei a pediø a outro santo, a não ser Deus, mais hoje: de jeito nenhum.

(05) Ah! Aí é uma pergunta bonita mas aí eu num sei se eu gostaria de ganhar porque eu [gos] ê ê eu um tipo seguinte e gosto da ê ê eu sou humilde, sou pobre eu gosto de tá no meio do povo, numa feira e e e viajar e ninguém me < perturba $>$ não tem nada agora se eu tirasse na loteria aí eu ia me perturbar porque a gente fica com medo tem que arrumar segurança e num sei quê.

A função exemplificativa de tipo tem propósito de introduzir exemplos ou enumerar elementos de uma sequência. A ocorrência (04) apresenta o tipo com função exemplificativa, em que a informante afirma que faz promessa para Deus, mas, por exemplo, para um santo qualquer ela não faz.

Já a ocorrência (05) demonstra um exemplo em que tipo foi utilizado pelo informante na tentativa de reorganizar a sua fala, exercendo função de marcador discursivo. A função de marcador discursivo é assim considerada porque o elemento marca uma sequência lógico-discursiva, conectando dois eventos.

De acordo com a tabela 02, há uma maior ocorrência do tipo com função exemplificativa, já que houve 22 (vinte e duas) de um total de 30 (trinta) ocorrências. Também encontramos 07 (sete) ocorrências de tipo conectivo e 01 (uma) ocorrência de tipo com função de marcador discursivo.

A função de tipo como conector comparativo ocorre quando este item linguístico conecta dois componentes informacionais e estabelece entre eles um vínculo comparativo. Considerando tal afirmação, na seção, a seguir, será feita a análise de tipo com a função de conector comparativo.

\subsection{O tipo na função de conector comparativo}

Nesta seção, descrevemos e analisamos os usos de tipo com função de conector comparativo no corpus VALPB através dos princípios desenvolvidos por Hopper (1991) e de discussões feitas por linguistas funcionalistas já mencionados em nosso trabalho.

Obtivemos 07 (sete) ocorrências de tipo com função de conector comparativo, conforme apresentamos, a seguir:

(06) I* Bom, eu acho que: antes de tudo [cê] deve se dedicáø aos estudos, né? você tem que chegáø e: + leváø a sério + o: que os professores + nos aconselham na na (gaguejo) sala de aula, é: procuráø se atualizáø, não tá, não ficáø estagnado, né? nos assuntos. $<$ A sep $>$ Sempre que um professôø passáø um um assunto você não ficáø só com aquilo, você i:ø mais além, procuráø + é: + mais + é: poderia dizêø, + um assunto bem mais profundo do o que o que ele passôø, + porque ele ali ele apenas + dá: tipo uma introdução. Você é quem deve chegáø e procuráø o desenvolvimento + da coisa. É: eu acho + que: é por aí: você tem que estudáø, tem que sêø um cara forte, é: corajoso, porque é uma [ma-] é uma área, a Educação Física que:, + como acho que muitas ôøtras + num num tem um bom rendimento, + é, levando pra relação do do do lucrativo, né? você num ganha muito bem, num é muito valorizado, infelizmente.

(07) E* Das escolas que você estudou, qual a que mais gostou?

I* Da Escola Técnica Federal da Paraíba. Eu terminei lá. Uma uma é um grupo mais assim uma [equi] tipo uma equipe, né? Mais organizada. A escola técnica os professores, realmente se apegam com os alunos.

$\mathrm{Na}$ ocorrência (06) o termo tipo funciona como conector comparativo, uma vez que o falante, explicando a importância de um aluno se dedicar aos estudos fora da sala de aula, pois o professor não aborda o assunto de maneira aprofundada, compara a maneira que este ministra o conteúdo a uma introdução. Pensando no que propõe Hopper (1991), seria possível afirmar que, durante o processo de gramaticalização do termo tipo, ocorre o princípio de estratificação, tendo em vista que uma nova camada (tipo) emergiu dentro do domínio funcional das conjunções comparativas, mas 
as camadas velhas, ou seja, as conjunções comparativas que já existiam na língua não foram descartadas, coexistindo com a camada nova. Exemplos de conjunções comparativas consideradas tradicionais que são utilizadas pelos falantes do português brasileiro são: como, tal como, como se, entre outras.

Ao mesmo tempo, recorrendo a Martelotta (2011), podemos ver que houve um mecanismo de extensão ou generalização de contextos, uma vez que a partir da habilidade que o falante possui de utilizar uma palavra já existente na língua, com função de substantivo, criou um novo significado, com função de conjunção comparativa. O termo tipo, com este novo significado, passa a competir com itens que já existiam associados a esses significados, conjunções comparativas como as mencionadas.

Da mesma forma, na ocorrência (07) o informante utiliza o item tipo com função de conector comparativo. Ao responder qual o colégio em que mais gostou de estudar, o informante diz que foi a Escola Técnica Federal da Paraíba, tendo em vista que as pessoas que de lá faziam parte trabalhavam como uma equipe.

Nessa ocasião, também vemos o enquadramento do tipo ao princípio de estratificaşão, porque apesar de haver o surgimento do tipo (conector comparativo), o tipo-originário ainda permanece na língua portuguesa, não havendo o seu desaparecimento e passando a interagir com camadas novas. O mecanismo de extensão, apresentado por Martelotta (2011) se faz presente na medida em que o novo significado de tipo passa a competir com os itens que já existiam associados a esses significados, conjunções comparativas tradicionais.

Através desses dados, percebemos o nível de atuação do termo tipo, que sofre uma mudança de categoria lexical, plena, autônoma e com bastante expressividade discursiva, que antes funcionava, conforme pudemos ver no dicionário virtual (2009), como um substantivo, para uma categoria gramatical, mais dependente dos outros elementos presentes na sentença, sendo constituída de um valor textual e discursivo mais forte. Tal fato nos remete ao que é defendido por Heine e Reh (1984 apud HEINE et al., 1991), pois, segundo os autores, quando uma unidade linguística passa pelo processo de gramaticalização, perde complexidade semântica, já que deixa de funcionar como uma categoria lexical, que representa algo no mundo. $\mathrm{O}$ item se destitui de sua carga semântica original, assumindo caráter (cada vez) mais gramatical, transitando de um sentido mais concreto para um mais abstrato, numa trajetória que poderia ser assim especulada: léxico $>$ sintaxe $>$ texto.

A utilização de tipo com função de conector comparativo também é vista nas ocorrências (08) e (09) e (10):

(08) $\mathrm{E}^{*} \mathrm{E}$ o que a gente pode dizêø que se ganha com esses gibis, em termos de conhecimento, até os temas assim abordados [né-] nessas histórias?

I* Ganha, ganha e muito. É: o pessoal, infelizmente, assim, as pessoas que + não lêem, né? + não entendem, + ficam criticanøo, né? Acham que é, aquilo ali é, como eu falei, assim, eles acham que é tipo uma coisa pra criança. Em resumo é isso, o pessoal que não conhece, né? Mays tão muito erradas, assim. Você lê, eles têm, + trayz várias informações, principalmente de, + assim, de ôøtros países, né? Você passa a conhecêø coisas, é: lugares, + costumes, né? que você não conhecia.

(09) $\mathrm{E}^{*}$ Vânia, o que você faria pelo bairro?

I* Pelo bairro? Acho que eu [fa] a primeira coisa que eu faria aqui nesse bairro era construir uma creche aqui. Tem tanta da menina por aqui que tem filho que num :: num tem aonde deixar o filho pra trabalhar nem nada. E aqui num tem uma creche, um berçário, deixar essas criancinhas que :: principalmente meu sobrinho, pra lá. Como eu falei, né, aqui mesmo teve uma garota que viajou foi para o Rio. Ela aqui ela num conseguia trabalho de jeito nenhum Teve que levar o pirralho dela porque tentou aqui, né, trabalhar, e num tinha [co] quem deixar [a] o menino. Foi na creche por aí tudinho, mas não tinha vaga. Ela foi embora pro Rio de Janeiro, eu fiquei morrendo de pena por [ca] do bichinho. E acho que pelo bairro eu faria isso, uma creche tipo berçário, tudo do bom, do melhor pras crianças. É isso. 
(10) A gente resolveu se juntáø mesmo, né? Que a gente num: + quanøo eu boli com ela, a gente não dormia junto, cada um na sua casa, a gente era tipo namorado, né? cada um na sua casa. \{inint\} a promotora disse, né? "você não tem o direito de i:ø dormiø com ela nem, enquanto você não resolveø assumi:ø ela".

Nos dados apresentados em (08) vemos uma situação em que o entrevistado fala sobre a importância da leitura de gibis, afirmando que muitas pessoas não fazem a leitura desse tipo de texto porque o comparam a algo que é destinado apenas a crianças. Para estabelecer essa comparação, o informante utiliza o item tipo, que funciona como conector, pois articula a informação ler gibis a coisa para crianças.

O processo de gramaticalização: tipo (substantivo) > tipo (conector) nos remete ao segundo princípio de Hopper (1991), o da divergência, uma vez que a forma lexical tipo (substantivo) se gramaticaliza e, mesmo assim, seu uso lexical permanece autônomo, resultando no surgimento de múltiplas funções de mesma etimologia que, embora divergentes, convivem numa mesma sincronia.

Também associamos esse processo ao princípio de decategorização, proposto por Hopper (1991), já que a partir da gramaticalização, o termo tipo neutraliza as marcas de categoria plena e passa a assumir características de categoria secundária, de conjunção, havendo a migração de uma categoria menos gramatical para outra, mais gramatical, embora o sentido de tipo como substantivo não tenha desaparecido, conforme vimos através do princípio de divergência.

Em (09), a entrevistada, ao responder o que faria pelo bairro em que mora, diz que construiria uma creche que funcionaria como uma espécie de berçário. Ao fazer essa comparação, utiliza o item tipo com função de conector. Tal ocorrência demonstra a neutralização das marcas de tipo como categoria plena. O tipo assume características de categoria secundária, de conjunções, havendo a migração de uma categoria menos gramatical para outra, mais gramatical, tal como já foi mencionado.

$\mathrm{Na}$ ocorrência (10) identificamos mais uma vez o princípio de decategorização, proposto por Hopper (1991). O informante utiliza tipo para falar da sua relação com outra pessoa, dizendo que era íntima como se fossem namorados. Assim, o item funciona como conector comparativo, já que há a comparação do seu relacionamento a um relacionamento entre namorados, tendo como consequência a neutralização das marcas de tipo como categoria plena (substantivo) e passando a assumir características de categoria secundária (conector).

Com base no dado (11), vejamos a ocorrência do princípio de persistência por que passa o item tipo, no processo de gramaticalização:

(11) E* Você faria um ôøtro curso para ganháø mais dinheøro, por quê?

I* Faria ôøtøo curso para ganháø dinheøro, porque aparecenøo oportunidade, né? Um curso $<$ tipo $>$ hoje em dia que o pessoal $<$ fazenøo $>$ que tá fazenøo Direito, tá tendo $<$ vários> várias oportunidades, né? De emprego como juiz e tudo, e é uma coisa que leva até a têø dinheøro, então eu acho que eu deøxaria, tenøo oportunidade para ganháø mais dinheøro, me sustentáø sozinho, têø uma condição financeøra estável como eu tenho ôø melhor do que tenho, eu deixaria contabilidade ôø faria os dois cursos, num é? Se fosse possível, se não, se o ôøtro me me me propusesse até financeøramente melhóø, eu deøxaria contabilidade, se não, ficaria nos dois.

$\mathrm{Na}$ ocorrência (11) o informante responde a pergunta feita pelo entrevistador acerca de fazer outro curso com a finalidade de ganhar mais dinheiro, afirmando que faria sim, se tivesse oportunidade. O entrevistado compara a escolha do curso que faria aos cursos acessíveis hoje em dia, como o de Direito, que gera oportunidades de empregos de alta remuneração, como o de juiz.

Podemos observar o princípio de persistência, proposto por Hopper (1991), no processo de gramaticalização do item linguístico analisado, pois, quando passou de lexical a gramatical, alguns traços de seu sentido original permaneceram, como, por exemplo, a ideia de igualdade ou algo parecido ao utilizarmos tipo com função comparativa. Podemos detectar tal aspecto quando 
observamos a associação do uso de tipo como conector comparativo com um dos significados de tipo como substantivo, presente no dicionário virtual, isto é, 'Modelo; o que se utiliza para fabricar outro igual ou parecido'. Nessa perspectiva, também podemos evidenciar que ao substituirmos o tipo (conector comparativo) por uma conjunção tradicional (como, como se etc), observamos o aspecto da igualdade, e não de inferioridade e superioridade contidos em outras conjunções comparativas (menor que, maior que etc).

Outra consequência do princípio de persistência é a de que na nova função adquirida, a gramatical, a permanência de traços de sua função original refletiu no uso gramatical da forma, como vemos no dado (12), a seguir:

\section{(12) $\mathrm{E}^{*} \mathrm{E}$ que sonhos você realizaria?}

I* Sonhos? Eu acho abririria pra mim um shopping, um shopping, talveyz, não seø se vai sêø um shopping tipo o Manaíra ali, um shopping. Abriria um mercado de trabalho para mim, fazeria uma viagem pøa Europa, pøa i:ø para: vamoø dizêø, têø mais cultura e deøxáø de de vêø tanta coisa feøa que a gente vê aqui; pessoas mal educadas [sem edu] (risos) sem educação que nóys vemos, né? então eu acho que faria uma cultura pra mudáø talveyz, quem sabe, é: entendêø um pôøquinho a cultura dos ôøtros e tentáø compreender essas pessoas que a gente vê aí, que tem gente que não sabe se comportáø em certos lugares, entendeu? É, gente grossa. (VALPB, Ensino Superior)

A fala exposta na ocorrência (12) apresenta como um de seus sonhos abrir um shopping que seja parecido com o Shopping Manaíra: '(...) um shopping como o Manaíra ali'. Esse recorte nos mostra que a forma tipo pode assumir mais de uma posição na sentença, por exemplo: '(...) um shopping tipo o Manaíra ali', '(...) tipo o shopping Manaíra', sem que o sentido se altere. Nesse caso, o item revela guardar traços de sua atuação como substantivo, com maior possibilidade de flutuação do termo shopping na estrutura da oração.

As ocorrências encontradas no corpus VALPB corroboram o fato de que, no processo de gramaticalização, a mudança tenderá a se desenvolver de um sentido mais concreto para mais abstrato, tal como defende Neves (2002), pois o tipo conector possui um sentido mais abstrato em relação ao tipo com função de substantivo.

Além disso, o processo por que passa o item tipo, ratificado através dos princípios de Hopper (1991), deixa claro o fenômeno de gramaticalização do item, ao mover-se de uma categoria lexical para categorias gramaticais e discursivas tipo (substantivo) > tipo (conectivo); tipo (exemplificativo); tipo (marcador discursivo), no entanto, ainda convivendo de modo sincrônico com sua categoria original (a de substantivo).

\section{CONSIDERAÇÕES FINAIS}

O presente estudo evidenciou, no que diz respeito à frequência dos usos de tipo, que embora sua recorrência de uso como conectivo comparativo tenha sido menor em relação aos itens comparativos mais tradicionais, o item vem sendo utilizado não somente em contextos orais informais de uso do português brasileiro, mas também está presente em contextos mais formais, a exemplo das entrevistas que foram objeto de análise.

A identificação das ocorrências do item tipo nas categorias lexical e gramatical nos corpus nos deu alicerce para explicação do fenômeno de gramaticalização. Apesar de os falantes do português brasileiro fazerem uso do item em questão com sua função morfossintática de origem inserida na categoria lexical, foi justamente o uso constante e criativo do item pelos falantes que o fez adquirir funções gramaticais com vistas a uma maior produtividade e eficácia da comunicação, tornando-o mais abstrato. A gramaticalização deste item ainda pôde ser comprovada através de seu enquadramento aos princípios elencados por Hopper (1991), funcionando de modo eficiente na atividade comunicacional.

O estudo também evidenciou que os falantes do português brasileiro fazem uso de tipo com outras funções morfossintáticas, além das conectivas comparativas, como as exemplificativas e de 
marcadores discursivos em relação ao primeiro, além da permanência de uso com suas funções lexicais de origem.

Como havíamos enfatizado em nossa introdução, os estudos até então desenvolvidos sobre o item tipo advinham de regiões do Sudeste do país, o que tornava oportuno se fazer uma análise e registro do comportamento deste item na cidade de João Pessoa, Paraíba. Nesse sentido, nossa pesquisa pôde contribuir ao ter sido desenvolvida uma análise do comportamento local do item tipo, através da qual identificamos que os falantes de João Pessoa demonstraram a manifestação do processo de gramaticalização do referido item em suas falas.

\section{REFERÊNCIAS BIBLIOGRÁFICAS}

CEZARIO, Maria Maura et al. Funcionalismo linguístico: análise e descrição. São Paulo: Contexto, 2012.

FERREIRA, Aurélio Buarque de Holanda. Mini Aurélio. 4.ed. Rio de Janeiro: Nova Fronteira, 2000.

GIVÓN, Talmy. A compreensão da gramática. São Paulo: Cortez; Natal, Rio Grande do Norte: EDUFRN, 2012.

Syntax: a functional-typological introduction. Amsterdam: John Benjamins, 1990.

On understanding grammar. New York: Academic Press, 1979.

GONÇALVES, Sebastião Carlos Leite et al (org.). Introdução à gramaticalização: princípios teóricos e aplicação. São Paulo: Parábola, 2007.

HEINE, Bernd; CLAUDI, Ulrike; HÜNNEMEYER, Friederike. Grammaticalization: a conceptual framework. Chicago: The University of Chicago Press, 1991.

HEINE, Bernd. Grammaticalization as an explanatory parameter. In: PAGLIUCA, W. (Ed.) Perspectives on grammaticalization. Amsterdam: John Benjamins, 1994.

HEINE, Bernd.; KUTEVA, Tania. The Genesis of Grammar: A Reconstruction. Inglaterra: Oxford University Press, 2007.

HOUAISS, Antonio.; VILLAR, Mauro de Salles. Dicionário Houaiss da língua portuguesa. Rio de Janeiro: Objetiva, 2001.

HOPPER, Paul J. On some principles of grammaticalization. In: TRAUGOT'T, Elizabeth Closs \& HEINE, Bernd (eds.) Approaches to grammaticalization. Vol.I: Focus on theoretical and methodological issues. Amsterdam/Philadelphia: John Benjamins Publishing, 1991.

HOPPER, Paul. TRAUGOT'T, Elizabeth C. Grammaticalization. Cambrigde: Cambrige University Press, 1993.

HOPPER, Paul. Some recent trends in grammaticalization. Annual Review of Anthropology, v. 24, p. 217-236, 1996. 
MARTELOTTA, Mário Eduardo. Mudança Linguística: uma abordagem baseada no uso. São Paulo: Cortez, 2011.

MEILLET, A. Linguistique historique et linguistique générale. Paris: Libraire Honoré Champion, 1948.

NEVES, Maria Helena Moura. A gramática funcional. São Paulo: Martins Fontes, 2001.

2002.

A gramática: história, teoria e análise, ensino. São Paulo: UNESP,

OLIVEIRA, Mariangela Rios de; VOTRE, Sebastião Josué. A trajetória das concepções de discurso e de gramática na perspectiva funcionalista. Matraga: Rio de Janeiro, v.16, n.24, jan.jun., 2009, p. 97-114.

Disponível em: < http:/ / wmm.lexico.pt/> Acesso em 06 de fevereiro de 2016

Recebido em 04/04/2017

Aceito em 23/05/2017

Publicado em 05/06/2017 